providing an elected representative on the district management team to promote the particular interest of each sector. The local administrative, financial, and nursing representatives complete the team to provide a balanced executive group. If the new system of health districts has this team at its helm, able to make executive decisions and answerable directly to the regional health authority, the system will work. The simple recipe for success must be that the district management team needs to be given its budget and then be master of its own destiny.

The area administrative system of the 1974 reorganisation has been a disaster for several reasons other than the obvious one of introducing a grey area of non-decision into the system. In my view one of the important reasons for the failure of area administration has been that it rests the representation of the medical profession on the shoulders of a single doctor. This single doctor, usually a community physician, is the sole medical representation on the area health authority's crucial executive committee, the area team of officers. I intend no criticism of community physicians here. It is simply that a community physician cannot be sufficiently familiar with the special problems of general or hospital practice any more than I, a consultant surgeon, can give sensible advice on a community psychiatric service. It is essential to retain the tripartite medical representation on the health district's executive committee to produce a balanced medical advice input.

I would urge the profession to do two things. (1) Be prepared to be involved in your own administration. It is in your own and your patient's interest because no lay person can or will do it for you properly. So read the Patients First and send your comments to the address given on page 23. (2) Insist that the new district administration's executive committee is the district management team and that its constitution remains the same as it is todaywith doctors who work in hospitals, general practice, and community medicine working together for the good of our patients-patients first.

RICHARD G NOTLEY

Farnham Road Hospital,
Guildford, Surrey GU2 5LX

SIR,-The emphasis on maximum delegation in the section on management in the hospital and in the community services referred to in the DHSS consultative paper Patients First is likely to be generally welcomed. It does not, however, go far enough. The treatment of patients in hospital takes place at ward level by a team headed by the consultant. The management of the whole ward, in which there are usually several consultant teams, is the responsibility of the sister or charge nurse; and staff providing support services in the ward should be made explicitly accountable to the sister in charge.

The proposal in paragraph 12(c) that "staff working within hospitals in non-clinical support functions should be accountable to the hospital administrator rather than to district level managers" will help, but the care of the patient will be greatly enhanced if the ward sister is officially made the local manager of the domestics and porters while they are working in her ward. The present monitoring role of the ward sister is too imprecise and leaves too much to chance.

\section{Where have all the nurses gone?}

SIR,-Nancy Arnold's article "Where have all the nurses gone?" (19 January, p 199) was like a breath of fresh air for those many doctors and few nurses who warned of the consequences of implementing the Salmon Report of 1966 in terms of loss of job satisfaction, recognition, and morale of nurses at the bedside. With the ward sister's essential role undermined subsequent inroads by nurse educators, domestic supervisors, trade union officials, and EEC bureaucrats alike have met little opposition.

Mrs Arnold's article should be made essential reading for all nurse and medical administrators, and a topic for debate by all who enter the nursing profession over the next few years.

J W Paulley

Department of Medicine,

Ipswich Hospital,

SIR,-The article "Where have all the nurses gone ?" by Nancy Arnold (19 January, p 199) in laying the blame for the ills of the nursing profession at the feet of enrolled and auxiliary nurses is in itself a further, albeit small, contribution to the decline of morale of nurses.

Hostility towards enrolled and auxiliary nurses is not limited to directors of nurse education (is this Salmonese for "tutor"?) but is found among many doctors. Their belief in the superiority of registered nurses is largely based on their ignorance of nurse education and should at any rate be quickly dispelled by experience. Enrolled and auxiliary nurses perform most of the basic care on the wards today and are competent. Enmity between groups of workers leads to loss of morale and its perpetuation by senior management must be harmful. Standards must surely be raised by a return to sensible selection of studentsbased not on academic achievement but on say, Ashdown's qualifications for a good nurse $^{1}:(a)$ a real love of attending to the sick and helpless; $(b)$ a strong constitution; and (c) an equable temperament.

Doctors are responsible for much of the decline in nursing. They have forgotten their duty to concern themselves with nurses' welfare. Comradeship between doctors and nurses is less evident. They failed to save nursing from Salmon. They fail now to protect nurses from intimidation and interference by nursing administrators. A renewed relationship between doctors and all working-that is, nonadministrative-nurses would be a start to getting a better and happier nursing profession.

D J TUPper

Southampton General Hospital,

Southampton, Hants

Ashdown AM. A complete system of nursing. London J M Dent, 1922 .

\section{The practice nurse}

SIR,-We have found most interesting the study of Dr W H R Walters and others (12 January, $p$ 87) concerning the work of the practice nurse. One of the things not mentioned was what happens to the extensive amount of paperwork engendered by the work of the practice nurse-for instance, in filling out laboratory forms, in sending off claims to the family practitioner committee, and in documenting important information such as on immunisations.

We noted that over a four-year period there are practice nurses working a total of 68 hours a week and seeing just under 44000 patients and it is not clear whether the secretarial duties were done by the practice receptionists, in which case the total hours involved would be considerably greater than 68 , or whether this work was done by the nurses themselves, in which case they would spend a fair amount of time in non-nursing duties.

Our own practice nurse has managed to see about 45000 patients in the last four years, working only a 40-hour week, with the simple expedient of having her own secretaryreceptionist. I am sure that this is the next step forward in the evolution of the practice nurse, particularly in health centres, where several practices may join together to employ both a practice nurse and her secretaryreceptionist. It takes a tremendous load of work off the other practice ancillary staff and also ensures that the nurse, an expensive item of employment, is fully occupied with skilful nursing duties alone.

Charles ReES

The Health Centre

Ferndown, Dorset BH22 9HB

\section{Domiciliary visits by consultants}

SIR,-While agreeing with some of the remarks of my friend Dr P E Jackson (26 January, p 256), I must state that I to a very large extent deprecate the fall-off in domiciliary visits in our area.

This has happened through no direction of our own and I think arises from various factors such as the expediency of the general practitioner, the fact that patients with dubious chest pain are best rapidly admitted to the coronary care unit, and, finally, the fact that many general practitioners now have their own electrocardiographs.

In the past, when a larger number of domiciliary visits were undertaken the work burden was considerable as it was usually late and out of hours and often involved much travel. However, the opportunity to meet a general practitioner in a patient's home is a privilege that I miss. When one has seen a patient in his or her home the problem of rehabilitation and follow-up is enormously simplified by the knowledge that one has acquired of the doctor, the family, and the environment. In addition, there is usually a mutual exchange of medical ideas, which is profitable and stimulating. In the absence of such meetings, increasingly general practitioners are again to hospital doctors just becoming a name at the bottom of a letter or a voice on the telephone. It does help to be able to put a face and a person to those with whom one is having important dealings.

In contrast with Dr Jackson, I find that general practitioners are not always good at deciding between admission and urgent outpatient appointments. Pulmonary oedema, that most distressing of symptoms, is frequently not diagnosed and treated urgentlythe usual diagnosis is bronchospasm and effective treatment is thereby delayed. Rapid atrial fibrillation even when confirmed by a practice electrocardiogram is often not treated without the blessing of a hospital visit. Both 